\title{
The relation between risk-taking behavior and alcohol use in young adults is different for men and women
}

\author{
L. de Haan ${ }^{\mathrm{a}, *}$, A.C.G. Egberts ${ }^{\mathrm{a}, \mathrm{b}}$, E.R. Heerdink ${ }^{\mathrm{a}, \mathrm{b}}$ \\ ${ }^{a}$ Division of Pharmacoepidemiology and Clinical Pharmacology, Utrecht Institute of Pharmaceutical Sciences, Utrecht University, Universiteitsweg 99, \\ 3584 CG Utrecht, The Netherlands \\ ${ }^{\mathrm{b}}$ Department of Clinical Pharmacy, University Medical Center Utrecht, Heidelberglaan 100, 3584 CX Utrecht, The Netherlands
}

\section{A R T I C L E I N F O}

\section{Article history:}

Received 7 April 2015

Received in revised form 7 July 2015

Accepted 10 July 2015

Available online 22 July 2015

\section{Keywords:}

Alcohol use

Risk-taking behavior

RT-18

Sex

Multinomial logistic regression

\begin{abstract}
A B S T R A C T
Objective: The present study examined the relationship of risk-taking behavior and alcohol use and the role of sex herein, while adjusting for age, depression, anxiety, stress and lifestyle. Methods: Participants were 6002 university students. They were classified as either abstinent, drinker but non-binge drinker, or binge drinker based on self-reported alcohol consumption. Risk-taking and risk assessment were evaluated with the RT-18 and depression, anxiety and stress with the DASS- 21 . Results: The odds of being a binge versus non-binge drinker increased with risk-taking as well as risk assessment for both men and women. The odds being a non-binge drinker versus abstinent were increased by risk-taking for women only. For binge drinking versus abstinence, risk-taking had a significant increasing effect for both sexes, but risk assessment was only significant in women.

Conclusion: These results may assist with alcohol use prevention techniques because risk-taking behavior exerts, even when corrected for age, lifestyle, depression, anxiety, and stress levels, a solid, sex-specific independent effect on alcohol use.
\end{abstract}

(C) 2015 Elsevier Ireland Ltd. All rights reserved.

\section{Introduction}

Nearly eight and four percent of all male and female deaths, respectively could be attributed to alcohol use worldwide in 2012 (World Health Organization, 2014). This sex difference is largely explained by variations in consumption: women are more often abstainers, drink alcohol less frequently and in smaller quantities, and are less often engaged in heavy episodic drinking (Dawson and Archer, 1992; World Health Organization, 2014).

This sex-specific pattern of alcohol use could also partly be explained by physical characteristics. Females need less alcohol to reach the same state of inebriety as men due to their average lower body weights, smaller liver capacities to metabolize alcohol, and higher proportions of body fat (Smarandescu et al., 2014; World Health Organization, 2014).

Psychological factors could also contribute to sex differences in alcohol use. A large body of research has identified that personality traits such as impulsivity and sensation seeking consistently correlate with alcohol use (Ball, 2005; Dick et al., 2010; Hittner and Swickert, 2006; Ibáñez et al., 2010). Sex differences in

\footnotetext{
* Corresponding author.

E-mail address: l.dehaan@uu.nl (L. de Haan).
}

risk-taking behavior and related personality traits are also well known, with men typically being more likely to engage in risky behavior than women (Byrnes et al., 1999). In general, men score higher on measures of behavioral disinhibition, impulsivity and sensation seeking, each of which correlate to heavy alcohol use and related problems (Nolen-Hoeksema, 2004; Rounsaville et al., 1998).

In addition to risk-taking behavior, psychiatric disorders have been linked to alcohol use (Ball, 2005; Rounsaville et al., 1998). An association between major depression and alcohol consumption exists, although the causality and direction of this relationship varies based on patient characteristics and is thus unclear (Boden and Fergusson, 2011). In general, women are twice as likely to experience depression as men (Nolen-Hoeksema and Girgus, 1994), implying different relations between alcohol use and depression based on the heavier alcohol consumption in men. Other psychiatric disorders that influence or coincide with alcohol use also have well known sex-related disparities. For instance, women are more likely to develop anxiety disorders (McLean and Anderson, 2009) and female problem drinkers have reported more serious depressive symptoms and health-related stressful events compared to males (King et al., 2003).

Sex differences in alcohol use can thus be attributed to physical and psychological factors, as well as psychiatric disorders. We 
were particularly interested in the relationship between risk-taking behavior, alcohol consumption and the role of sex herein in young adults. This age group is known to consume alcohol in dangerous levels (e.g., binge drinking or more than 4 (female)/5 (male) consecutive alcoholic consumptions) (Wechsler et al., 1995a,b) and have elevated levels of risk-taking behavior as well (Steinberg et al., 2008). Therefore, the present study examined the relationship between risk-taking behavior and alcohol use in a large sample of young male and female adults while adjusting for age, depression, anxiety, stress, and lifestyle. We hypothesized: (1) risk-taking behavior is significantly and positively related to alcohol use, even after adjustments for age, depression, anxiety, stress, and lifestyle and that (2) this relation is different for men and women.

\section{Material and methods}

\subsection{Participants}

Participants were 6002 students from the online Utrecht Student Survey (USS de Haan et al., 2012b), which has been extensively described elsewhere. In brief, the USS was conducted in June of 2011, among students from Utrecht University and the University of Applied Sciences Utrecht. These students were invited to participate via an internal university email. The aim of the survey was 3-fold: (1) to determine the potential impact of alcohol mixed with energy drinks (AMED) on overall alcohol consumption and alcohol-related consequences; (2) to investigate motivations for specific alcohol consumption patterns; (3) to identify personality characteristics, risk-taking behavior and their relationship with alcohol consumption. Data from this sample were previously analyzed for the purpose of evaluating AMED and alcohol consumption (de Haan et al., 2012a). Approximately 70,000 students received the email containing the link to the online survey. A total of 7158 students opened the link to the survey provided by email, yielding a response rate of $10.2 \%$. Respondents were first presented with the online informed consent form stating the purpose, procedures, risks, confidentiality, compensation, and contact information. To proceed, participants had to agree by clicking on the "I agree to participate" button. In case the participant chose to click the "I decline to participate" button, they were redirected to a thank you page, and the survey was shut down. After cleaning the data, 6002 students remained for analysis (de Haan et al., 2012b). A total of 39 were excluded for not giving consent; 570 did not meet the age criterion of 18-30 years; 525 did not answer the questions that were necessary to classify them as part of one of the drinking groups; and 22 stated they did not answer the items truthfully (de Haan et al., 2012b). From 6002 participants, $n=2116$ (35.3\%) were male and $n=3886$ (64.7\%) female.

\subsection{Alcohol consumption}

To assess alcohol consumption, items from the Quick Drinking Screen (Sobell et al., 2003) were adapted and measured in three possible drinking scenarios: consumption of just alcohol (i.e., beer or wine or unmixed liquor); consumption of alcohol mixed with energy drinks; and consumption of alcohol with other mixers (e.g., cola, juice, etc.). Participants were asked to report number of standard drinks, with $250 \mathrm{cc}$ of beer, $100 \mathrm{cc}$ of wine, and $35 \mathrm{cc}$ of liquor equal to one standard drink. For this analysis, alcohol consumption data from all three scenarios were combined into pooled alcohol consumption data. For those who used alcohol, consumption over the previous month (yes/no) and the occurrence of binge drinking days (yes/no) in the past month, were extracted. Binge drinking was defined as consuming more than four (females) or five (males) alcoholic beverages in one day. Subjects were classified as either abstinent, drinker but non-binge drinker, or binge drinker.

\subsection{Risk-taking behavior}

The Risk Taking questionnaire-18 items (RT-18; de Haan et al., 2011) consists of 18 dichotomous 'yes' or 'no' items taken from the Impulsiveness-VenturesomenessEmpathy questionnaire (Eysenck et al., 1985), the novelty-seeking subscale of the Temperament and Character Inventory (Cloninger et al., 1993), and the impulsivesensation-seeking subscale of the Zuckerman Kuhlman Personality Questionnaire (Aluja et al., 2006; Zuckerman, 2002). The RT-18 has two subscales: risk-taking and risk assessment (each subscale score consists of the sum of nine specific items, with three items reversely scored). Risk-taking scores are correlated with actual risktaking behavior (i.e., engagement in risky behaviors), whereas a high score on risk assessment indicates a low level or less consideration of possible consequences (i.e., acting without thinking). Cronbach's alpha was calculated in this sample. Risk-taking and assessment had internal consistencies of 0.79 , and 0.73 , respectively.

\subsection{Other measures}

Demographic information was collected regarding sex, age, height and weight. Depression, anxiety and stress levels were assessed with the Depression Anxiety
Stress Scales 21 items (DASS21; de Beurs et al., 2001; Lovibond and Lovibond, 1995) which is a quantitative self-report measure of depression, anxiety and stress. Example items include, "I found it hard to wind down" for the stress scale, "I was aware of dryness in my mouth" for the anxiety scale, and "I couldn't seem to experience any positive feeling at all" for the depression scale. Responses were based on a threepoint Likert-scale related to feelings over the past week. Cronbach's alphas were $0.87,0.76$, and 0.85 for depression, anxiety and stress, respectively. Lifestyle was based on BMI scores (i.e., dividing weight in kilograms by squared height in meters), membership in a fraternity or sorority (yes/no), illicit drugs use in the previous year (yes/no), current medication use (yes/no), and tobacco use (yes/sometimes/no).

\subsection{Data analysis}

Data were gathered in Excel and prepared for analyses using R version 3.0.2 (RCoreTeam, 2014) with Hmisc, Psych and Nnet packages. Sex differences were assessed through either independent $t$-tests or chi-square tests for age, weight, height, BMI, risk-taking, risk assessment, depression, anxiety, stress, fraternity or sorority membership, medication use, illicit drug use, tobacco use and alcohol use. The relation between risk-taking behavior and alcohol use was assessed in a hierarchical multinomial logistic regression model. Based on preliminary analysis where sex acted as an effect modifier, we stratified the analysis for sex. The crude model was corrected for possibly confounding variables in three steps. First, the crude model was corrected for age (model 1; Barnes et al., 2002; Feil and Hasking, 2008). The second model was adjusted for age and lifestyle (model 2). Lifestyle comprises BMI, fraternity or sorority membership, tobacco use, medication use and illicit drug use, which all are known confounders in the literature (Barnes et al., 2002; Capone et al., 2007; Kleiner et al., 2004; Reed et al., 2007). Third, the model was corrected for age, lifestyle, and DASS21 results (model 3; Buckner et al., 2011; Feil and Hasking, 2008). Dummy variables were created where necessary. Effect sizes were expressed as odds-ratios with $95 \%$ confidence intervals (95\%CI). A total of twelve determinants (including dummies) were included in the third model. This implies at least $12 * 15=180$ observations were needed to fulfill the power requirement. Male abstinents $(n=180)$ represented the category with the least members. Therefore, we met the prerequisite threshold. All statistical tests were two-sided. Effects with $p<0.05$ and confidence intervals that did not contain zero were considered significant.

\section{Results}

Sex differences are depicted in Table 1 . Men were slightly older $(t(4259)=4.16, p<0.001)$, heavier $(t(3920)=42.90, p<0.001)$, taller $(t(3927)=72.84, p<0.001)$, and had higher BMI scores $(t(4619)=7.44, p<0.001)$. For RT-18 scores, the difference was largest for risk-taking $(t(4259)=4.16, p<0.001)$ and substantially smaller for risk assessment $(t(4046)=2.06, p=0.04)$. There were no significant differences for depression $(t(2325)=1.80$, $p=0.07)$ and anxiety $(t(2424)=1.18, p=0.24)$. However, women had much higher stress scores $(t(2636)=-6.38, p<0.001)$. Sorority or fraternity membership yielded a small difference $\left(\chi^{2}(1)=5.54\right.$, $p=0.02$ ), whereas more women indicated medication use compared to men $\left(\chi^{2}(1)=241.47, p<0.001\right)$. Interestingly, more men reported tobacco $\left(\chi^{2}(2)=38.95, p<0.001\right)$ and illicit drug use $\left(\chi^{2}(1)=124.61, p<0.001\right)$. Men also reported more use of alcohol (91.5\%, $\left.\left(\chi^{2}(1)=20.56, p<0.001\right)\right)$ and $75.4 \%$ were classified as binge drinkers. A total of $87.6 \%$ of women reported alcohol use in the past month, and $59.5 \%$ were identified as binge drinkers, which was significantly lower percentage than that for men $\left(\chi^{2}(2)=154.99\right.$, $p<0.001)$. Fig. 1 shows the distribution of the RT-18 risk-taking and risk assessment scores for men and women in each of the three alcohol use categories.

Table 2 summarizes the results of the hierarchical multinomial logistic regression for males. The regression coefficients and odds ratios for the three contrasts are shown, including non-binge drinkers compared to abstinents, binge drinkers compared to nonbinge drinkers, and binge drinkers compared to abstinents. A highly significant effect of risk-taking on alcohol use was found for binge drinkers versus abstinents, and the final model (i.e., corrected for age, lifestyle and the DASS21 subscales) yielded an OR of 1.17. Interestingly, risk assessment did not significantly influence this male specific model for alcohol use. Just a small difference between nonbinge drinkers and abstinents (OR between 1.03 and 1.00 for all four models) was found, and the effect of risk-taking on binge drinkers 
Table 1

Descriptive statistics and sex differences.

\begin{tabular}{|c|c|c|c|c|c|}
\hline & Male & $n=2116$ & Female & $n=3886$ & $p$ \\
\hline & M & $(\mathrm{SD})$ & $M$ & $(\mathrm{SD})$ & \\
\hline Age in yrs & 22.2 & $(2.6)$ & 21.9 & $(2.5)$ & $<0.001$ \\
\hline Weight in $\mathrm{kg}$ & 77.7 & (11.5) & 64.9 & $(10.2)$ & $<0.001$ \\
\hline Height in $\mathrm{m}$ & 1.84 & $(0.1)$ & 1.71 & $(0.1)$ & $<0.001$ \\
\hline BMI & 22.9 & $(2.9)$ & 22.3 & $(3.1)$ & $<0.001$ \\
\hline \multicolumn{6}{|l|}{ RT18 } \\
\hline Risk-taking & 4.6 & $(2.7)$ & 3.4 & $(2.4)$ & $<0.001$ \\
\hline Risk assessment & 2.1 & $(2.0)$ & 1.9 & $(2.0)$ & $<0.05$ \\
\hline \multicolumn{6}{|l|}{ DASS 21} \\
\hline Depression & 2.9 & $(3.5)$ & 2.6 & $(3.4)$ & 0.07 \\
\hline Anxiety & 2.3 & $(2.7)$ & 2.2 & $(2.7)$ & 0.06 \\
\hline \multirow[t]{3}{*}{ Stress } & 3.4 & $(3.5)$ & 4.3 & $(3.8)$ & $<0.001$ \\
\hline & Male & $n=2116$ & Female & $n=3886$ & $p$ \\
\hline & $n$ & $(\%)$ & $n$ & $(\%)$ & \\
\hline Fraternity/sorority member & & & & & $<0.05$ \\
\hline No & 1663 & $(78.6 \%)$ & 3148 & $(81.2 \%)$ & \\
\hline Yes & 452 & $(21.4 \%)$ & 729 & $(19.3 \%)$ & \\
\hline Medication use & & & & & $<0.001$ \\
\hline No & 1872 & $(88.5 \%)$ & 2750 & $(70.8 \%)$ & \\
\hline Yes & 244 & $(11.5 \%)$ & 1136 & $(29.2 \%)$ & \\
\hline Illicit drug use & & & & & $<0.001$ \\
\hline No & 1418 & $(67.0 \%)$ & 3110 & $(80.0 \%)$ & \\
\hline Yes & 698 & $(33.0 \%)$ & 776 & $(20.0 \%)$ & \\
\hline Tobacco use & & & & & $<0.001$ \\
\hline No & 1443 & $(68.2 \%)$ & 2940 & $(75.7 \%)$ & \\
\hline Sometimes & 387 & $(18.3 \%)$ & 533 & $(13.7 \%)$ & \\
\hline Yes & 286 & $(13.5 \%)$ & 413 & $(10.6 \%)$ & \\
\hline Alcohol use & & & & & $<0.001$ \\
\hline Abstinent & 180 & $(8.5 \%)$ & 481 & $(12.4 \%)$ & \\
\hline Drinker, no binge & 340 & $(16.1 \%)$ & 1092 & (28.1\%) & \\
\hline Binge drinker & 1596 & $(75.4 \%)$ & 2313 & $(59.5 \%)$ & \\
\hline
\end{tabular}

versus abstinents ( $\mathrm{OR}=1.25$ in the crude model) was almost as large as that of risk-taking on binge drinkers versus non-binge drinkers ( $\mathrm{OR}=1.21$ crude model). Therefore, it seems that risk-taking predicted binge drinking and risky alcohol consumption. In model 3, the effect of binge drinker versus abstinent and binge drinker versus non-binge drinker were equal, and both ORs were 1.17 after all adjustments were made.
The risk assessment showed a significant effect in males for binge drinking versus non-binge drinking. Neither the risk-taking nor the risk assessment scales showed any effect on the non-binge drinking versus abstinent contrast.

When looking at the female model (Table 3), a slightly different outcome became apparent. Risk-taking yielded significant effects on all three contrasts, with ORs of 1.11 for non-binge drinkers
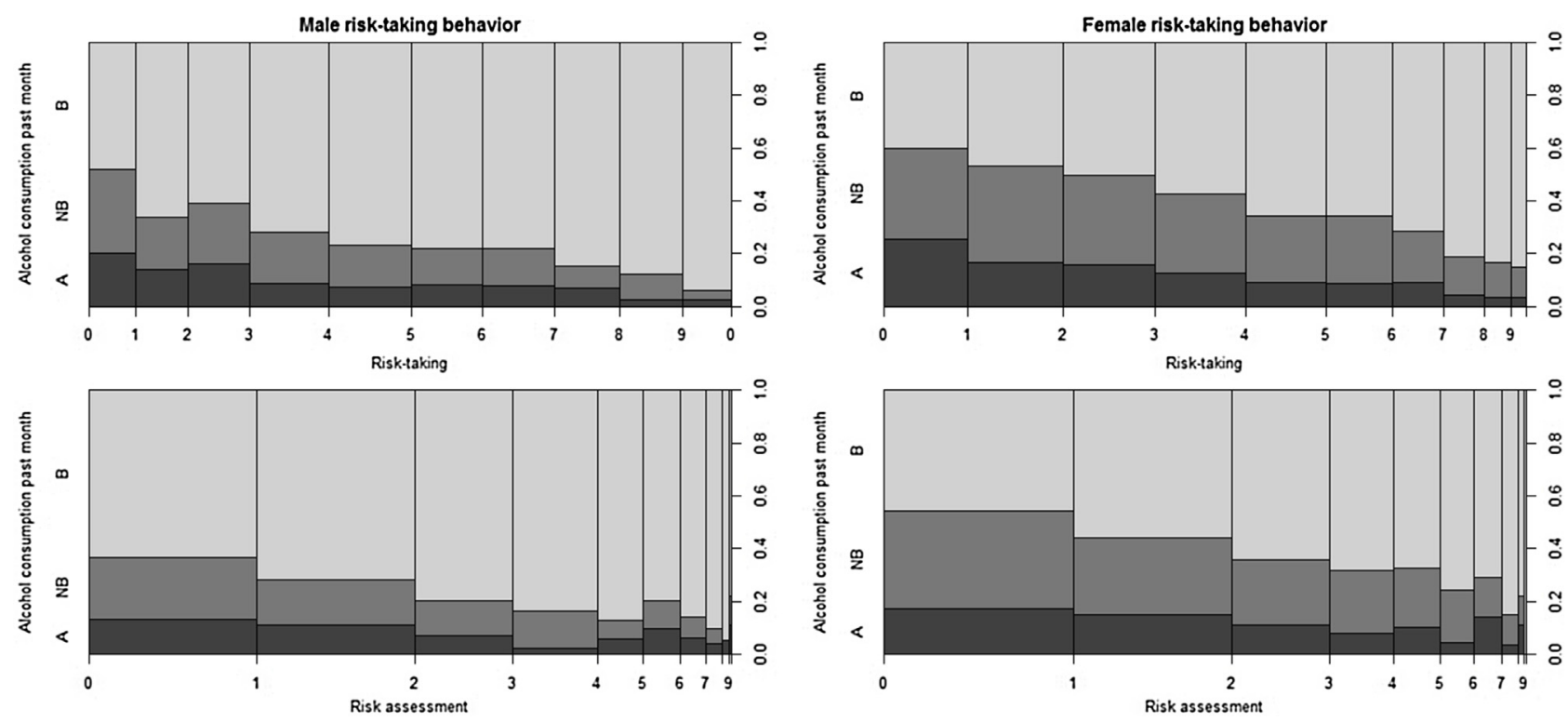

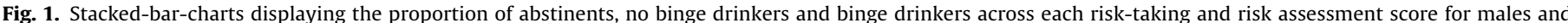

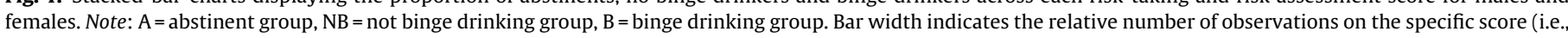
$0-9)$ on the risk-taking behavior scales. 
Table 2

Hierarchical multinomial logistic regression model for risk-taking behavior and alcohol use, $n=2116$ males.

\begin{tabular}{|c|c|c|c|}
\hline & $\begin{array}{l}\text { No binge drinker versus abstinent } \\
\text { OR }(95 \% \mathrm{CI})\end{array}$ & $\begin{array}{l}\text { Binge drinker versus not binge drinker } \\
\text { OR }(95 \% \mathrm{CI})\end{array}$ & $\begin{array}{l}\text { Binge drinker versus abstinent } \\
\text { OR }(95 \% \mathrm{CI})\end{array}$ \\
\hline \multicolumn{4}{|l|}{ Model crude } \\
\hline Risk-taking & $1.03(0.96 ; 1.12)$ & $1.21(1.15 ; 1.26)$ & $1.25(1.17 ; 1.34)$ \\
\hline Risk assessment & $0.97(0.86 ; 1.12)$ & $1.17(1.08 ; 1.16)$ & $1.25(1.02 ; 1.24)$ \\
\hline \multicolumn{4}{|c|}{ Model 1 ; adjusted for age } \\
\hline Risk-taking & $1.03(0.96 ; 1.12)$ & $1.21(1.15 ; 1.28)$ & $1.26(1.17 ; 1.34)$ \\
\hline Risk assessment & $0.97(0.86 ; 1.09)$ & $1.16(1.08 ; 1.26)$ & $1.12(1.02 ; 1.24)$ \\
\hline \multicolumn{4}{|c|}{ Model 2; adjusted for age and lifestyle* } \\
\hline Risk-taking & $1.01(0.93 ; 1.09)$ & $1.16(1.10 ; 1.23)$ & $1.17(1.09 ; 1.26)$ \\
\hline Risk assessment & $0.97(0.87 ; 1.10)$ & $1.10(1.01 ; 1.19)$ & $1.07(0.97 ; 1.18)$ \\
\hline \multicolumn{4}{|c|}{ Model 3; adjusted for age, lifestyle*, depression, anxiety, and stress } \\
\hline Risk-taking & $1.00(0.91 ; 1.10)$ & $1.17(1.09 ; 1.26)$ & $1.17(1.08 ; 1.27)$ \\
\hline Risk assessment & $0.96(0.83 ; 1.11)$ & $1.16(1.05 ; 1.29)$ & $1.12(0.99 ; 1.26)$ \\
\hline
\end{tabular}

Note: Lifestyle comprises BMI, fraternity or sorority membership, tobacco use, medication use and illicit drug use.

compared to abstinents, 1.12 for binge versus non-binge drinking, and 1.24 for binge drinking versus not drinking at all in the final corrected models. Risk assessment, however, had a significant effect on binge drinking versus abstinence, as well as on binge drinking versus non-binge drinking. The ORs for these relationships were 1.09 and 1.16 , respectively.

Interestingly, a correction for age in model 1 versus the crude model did not seem to affect the relation between risk-taking or risk assessment and alcohol use. Controlling for lifestyle variables, BMI, smoking, illicit drug use, medication use and membership in a fraternity or sorority, however, exerted the largest effect on this relationship (i.e., model 2 versus 1 ). The final correction with depression, anxiety and stress added to the list of confounders resulted in a slight change of regression coefficients (model 3 versus 2 ), particularly for risk assessment.

In addition to controlling for several confounders, we explored possible moderating effects in an additional model that included age * risk-taking, illicit drug use* risk-taking, tobacco use* risktaking, fraternity or sorority membership* risk-taking, age* risk assessment, illicit drug use * risk assessment, tobacco use * risk assessment, fraternity or sorority membership* risk assessment, and risk-taking * risk assessment. No significant modifying effects were found for men. We did find significant modifying effects for women, except for the risk assessment subscale. Risk-taking, however, was moderated in all three contrasts by the use of illicit drugs (non-binge drinker versus abstinent: $\mathrm{OR}=1.67$, $95 \% \mathrm{CI}=1.05 ; 2.67$; binge drinker versus non-binge drinker or abstinent: $\mathrm{OR}=1.62,95 \% \mathrm{CI}=1.03 ; 2.56)$. Specifically, illicit drug use slightly increased the OR (non-binge drinker versus abstinent: $\mathrm{OR}=1.82,95 \% \mathrm{CI}=1.09 ; 3.05$; binge drinker versus non-binge drinker: $\mathrm{OR}=1.06,95 \% \mathrm{CI}=0.94 ; 1.20$; binge drinker versus abstinent: $\mathrm{OR}=1.93,95 \% \mathrm{CI}=1.16 ; 3.21)$. Sorority membership mediated the effect between risk taking and alcohol use for non-binge drinker versus abstinent $(\mathrm{OR}=0.81,95 \% \mathrm{CI}=0.66 ; 0.99)$. Specifically sorority membership increased the OR for the binge drinkers versus non-binge drinkers $(\mathrm{OR}=1.25,95 \% \mathrm{CI}=1.10 ; 1.42)$. Nonsorority membership mediated the OR for risk-taking on all three alcohol consumption contrasts, but in different directions (nonbinge drinker versus abstinent: $\mathrm{OR}=1.14,95 \% \mathrm{CI}=1.07 ; 1.23$; binge drinker versus non-binge drinker: $\mathrm{OR}=1.10,95 \% \mathrm{CI}=1.04 ; 1.15$; binge drinker versus abstinent: $\mathrm{OR}=1.26,95 \% \mathrm{CI}=1.01 ; 1.18$ ).

\section{Discussion}

The aim of this study was to assess the relationship between risk-taking behavior, alcohol use and sex. Results showed risktaking behavior to be significantly related to alcohol use in both sexes, even after controlling for age, lifestyle, depression, anxiety, and stress levels.

More specifically, the odds of binge versus non-binge drinking or abstinence increased 4.12 times for males with the highest score on the risk-taking subscale. This difference was 2.77 in women. The odds of non-binge drinking versus abstinence were 2.56 times higher for high-risk takers. However this effect was only found for women.

Interestingly, the risk assessment subscale yields slightly weaker relations with the alcohol outcome of our model. When adjusted for age, lifestyle and the DASS-21 subscales, the odds of binge versus non-binge drinking was 3.80 times higher for men with a high score on risk assessment (i.e., minimal consideration of the consequences of certain behavior). For women with high risk assessment scores, odds of binge versus non-binge drinking, and binge drinking versus abstinence, were 3.80 and 2.17 , respectively.

Table 3

Hierarchical multinomial logistic regression model for risk-taking behavior and alcohol use, $n=3886$ females.

\begin{tabular}{|c|c|c|c|}
\hline & $\begin{array}{l}\text { No binge drinker versus abstinent } \\
\text { OR }(95 \% \mathrm{CI})\end{array}$ & $\begin{array}{l}\text { Binge drinker versus not binge drinker } \\
\text { OR }(95 \% \mathrm{CI})\end{array}$ & $\begin{array}{l}\text { Binge drinker versus abstinent } \\
\text { OR }(95 \% \mathrm{CI})\end{array}$ \\
\hline \multicolumn{4}{|l|}{ Model crude } \\
\hline Risk-taking & $1.12(1.06 ; 1.18)$ & $1.18(1.14 ; 1.23)$ & $1.32(1.25 ; 1.39)$ \\
\hline Risk assessment & $0.96(0.90 ; 1.03)$ & $1.18(1.12 ; 1.23)$ & $1.13(1.07 ; 1.21)$ \\
\hline \multicolumn{4}{|c|}{ Model 1 ; adjusted for age } \\
\hline Risk-taking & $1.12(1.06 ; 1.18)$ & $1.18(1.14 ; 1.22)$ & $1.32(1.25 ; 1.39)$ \\
\hline Risk assessment & $0.96(0.90 ; 1.03)$ & $1.18(1.13 ; 1.23)$ & $1.14(1.07 ; 1.21)$ \\
\hline \multicolumn{4}{|c|}{ Model 2; adjusted for age and lifestyle* } \\
\hline Risk-taking & $1.09(1.03 ; 1.16)$ & $1.12(1.08 ; 1.17)$ & $1.23(1.16 ; 1.30)$ \\
\hline Risk assessment & $0.94(0.88 ; 1.01)$ & $1.12(1.06 ; 1.17)$ & $1.05(0.99 ; 1.12)$ \\
\hline \multicolumn{4}{|c|}{ Model 3; adjusted for age, lifestyle*, depression, anxiety, and stress } \\
\hline Risk-taking & $1.11(1.04 ; 1.19)$ & $1.12(1.06 ; 1.17)$ & $1.24(1.17 ; 1.32)$ \\
\hline Risk assessment & $0.94(0.86 ; 1.02)$ & $1.16(1.10 ; 1.24)$ & $1.09(1.01 ; 1.18)$ \\
\hline
\end{tabular}

Note: Lifestyle comprises BMI, fraternity or sorority membership, tobacco use, medication use and illicit drug use. 
The independent effects of risk-taking and risk assessment on alcohol use are small, but significant for one point increase on the RT-18 subscales. However, this ranges from zero to nine points across all subscales and the effects of risk-taking behavior on alcohol consumption become much clearer in the latter. Moreover, we found slight differences between sexes. These sex differences may be partially explained by double standards for alcohol use between males and females. de Visser and McDonnell (2012) found women modified their alcohol consumption patterns to maintain a desired gender identity because drinking in general tends to be perceived as a masculine activity. The literature on alcohol consumption and risk-taking behavior in men and women reports mixed evidence for involvement of risk-taking behavior in regard to men and women. Sub-traits of risk-taking behavior, such as behavioral under-control, impulsivity and sensation seeking, have been shown to relate to alcohol use and problems for men, but less consistently for women (Nolen-Hoeksema, 2004). In a longitudinalepidemiological study, problems with behavioral control assessed at age 3 were found to correlate with alcohol-related problems at age 21 in men, but not women (Caspi et al., 1996). Behavioral under-control, assessed with the novelty-seeking subscale of the Tridimensional Personality Questionnaire and impulsiveness scale from the Eysenck Personality Inventory, was positively associated with heavy drinking in young adult men, but not in women (Rutledge and Sher, 2001). Our finding that high levels of risk-taking and low levels of risk assessment significantly increase the risk of binge drinking over abstinence and non-binge drinking in men are in line with the literature. However, we also found a significant effect of risk-taking behavior on alcohol consumption in women. Although this is not in concordance with the above-mentioned studies, other studies found risk-taking behavior to increase the level of alcohol consumption in women. For example, Parent and Newman (1999) found sensation seeking to play a mediating role in the relation between alcohol use and associated risk-taking behavior in a small group of women aged 21-22 years (Parent and Newman, 1999).

The relationship between risk-taking behavior and alcohol use in women has not been widely studied. The combination of the large dataset, the proportion of females present, and adjustment for risk-taking and risk assessment confounders in our study lend support to the finding that risk-taking behavior plays a significant role in dangerous alcohol consumption patterns in females. This finding and the fact that the effects of risk-taking behavior on alcohol consumption differed in men and women could serve as a point of interest for alcohol prevention techniques. Risk-taking behavior exerts, even when corrected for numerous confounders, a solid independent effect on alcohol use, mainly increasing the odds of binge compared to non-binge drinking and abstinence for men and women, as well as increasing the odds of non-binge drinking versus abstinence for women.

A few limitations should be noted. First, this study depended solely on self-report, which may have limited reliability. However, research indicates that such data become more reliable as the level of anonymity increases (Buchanan and Smith, 1999). We have used data from the USS, an online survey that was completely anonymous. Further, we asked participants if they had truthfully responded to all items and deleted those participants who did not to maximize reliability. Another limitation was the use of cross-sectional data (the USS), preventing the ability to determine causality between risk-taking behavior and alcohol use. Furthermore, these analyses were performed on Dutch students from the university of Utrecht, potentially limiting the generalizability of our results (e.g., effect sizes). However, the relation between risk-taking behavior and alcohol use has been well established in the literature, and it is likely that these effects will be found in campus sites and similar settings across the western world. We have compared our descriptive data with that of the entire population of Utrecht Students. In 2011, 59\% of first-year students at Utrecht University were female (Utrecht University, 2013). The characteristics of the current sample reflect those of the general student population at Utrecht University (de Haan et al., 2012a,b). The Dutch Ministry of Education Culture and Science stated that in 2011, 48\% of students in higher education in the Netherlands were male and $52 \%$ female (Onderwijs in cijfers [Education in numbers], 2013). Therefore, our sample deviates from these percentages. Moreover, in 2011, just $40 \%$ of $25-34$-year olds pursued higher education. We have no other data available to compare our data against the broader 18-30-yearold population in the Netherlands. However, if we compare our data to national alcohol consumption data from the National Health Monitor 2012 (NHM: Van Laar et al., 2012), 86\% of 19-30-year-olds reported alcohol consumption in the past 12 months nationwide, which resembles closely our percentage of $89 \%$. According to the NHM's definition of heavy drinking (at least once a week consumption of six or more alcoholic beverages for men and four or more alcoholic beverages for women), 18.5\% could be classified as heavy drinkers. We cannot directly compare this percentage to sample, as the definition we have used refers to more than 4 (for women) or 5 (for men) alcoholic beverages in the previous month. Another factor that might interfere with our estimation of the independent effect of risk-taking behavior on alcohol consumption is the inability to classify subjects as problematic drinkers or having an alcohol use disorder due to the monthly timeframe used in our study. Finally, we must note that when performing the effect modification analysis, we did have sufficient power to detect any effect modification for the male abstinent group, for it consisted of $n=180$ abstinents. However, we needed $15^{*} 23=345$ abstinent males. We did find a small significant modification effect for women. Therefore, this effect should be investigated using a larger abstinent male group.

In conclusion, risk-taking behavior has a small, but significant independent effect on alcohol use in a large sample of young adults. These results indicate different associations between risk-taking behavior and alcohol use for men and women. For men, risk-taking increases the likelihood of belonging to the binge versus non-binge drinking or abstinent group. Risk assessment was only significant for binge versus non-binge drinkers. For women, both risk-taking and risk assessment increased the likelihood belonging to the binge drinking category. Risk-taking also showed an effect on non-binge drinking versus abstinence in women.

\section{Role of funding source}

The Utrecht Student Survey was supported by a grant from Red Bull GmbH (Fuschl am See, Austria). Red Bull GmbH was not involved in the design and implementation of the study; collection, management, analysis, and interpretation of the data, nor with preparation of this manuscript.

\section{Contributors}

Author de Haan designed the study which contributed data to this article, and conducted the statistical analyses. Authors Egberts, Heerdink and de Haan contributed to the interpretation of results. Author De Haan wrote the initial draft of the manuscript and all authors contributed to and have approved of the final manuscript.

\section{Conflict of interest}

No conflict declared. 


\section{References}

Aluja, A., Rossier, J., García, L.F., Angleitner, A., Kuhlman, M., Zuckerman, M., 2006 A cross-cultural shortened form of the ZKPQ (ZKPQ-50-CC) adapted to English, French, German, and Spanish languages. Pers. Indiv. Differ. 41, 619-628.

Ball, S.A., 2005. Personality traits, problems, and disorders: clinical applications to substance use disorders. J. Res. Pers. 39, 84-102.

Barnes, G.M., Welte, J.W., Hoffman, J.H., 2002. Relationship of alcohol use to delinquency and illicit drug use in adolescents: gender, age, and racial/ethnic differences. J. Drug Issues 32, 153-178.

Boden, J.M., Fergusson, D.M., 2011. Alcohol and depression. Addiction 106, 906-914.

Buchanan, T., Smith, J.L., 1999. Using the internet for psychological research: personality testing on the world wide web. Br. J. Psychol. 90, 125-144.

Buckner, J.D., Ecker, A.H., Proctor, S.L., 2011. Social anxiety and alcohol problems: the roles of perceived descriptive and injunctive peer norms. J. Anxiety Disord. 25, 631-638.

Byrnes, J.P., Miller, D.C., Schafer, W.D., 1999. Gender differences in risk taking: a meta-analysis. Psychol. Bull. 125, 367-383.

Capone, C., Wood, M.D., Borsari, B., Laird, R.D., 2007. Fraternity and sorority involvement, social influences, and alcohol use among college students: a prospective examination. Psychol. Addict. Behav. 21, 316-327.

Caspi, A., Moffitt, T.E., Newman, D.L., Silva, P.A., 1996. Behavioral observations at age 3 years predict adult psychiatric disorders: longitudinal evidence from a birth cohort. Arch. Gen. Psychiatry 53, 1033-1039.

Cloninger, C.R., Svrakic, D.M., Przybeck, T.R., 1993. A psychobiological model of temperament and character. Arch. Gen. Psychiatry 50, 975.

Dawson, D.A., Archer, L., 1992. Gender differences in alcohol consumption: effects of measurement. Br. J. Addict. 87, 119-123.

de Beurs, E., Van Dyck, R., Marquenie, L.A., Lange, A., Blonk, R.W.B., 2001. De DASS Een vragenlijst voor het meten van depressie, angst en stress. Gedragstherapie $34,35-54$.

de Haan, L., de Haan, H.A., van der Palen, J., Olivier, B., Verster, J.C., 2012a. Effects of consuming alcohol mixed with energy drinks versus consuming alcohol only on overall alcohol consumption and negative alcohol-related consequences. Int. J. Gen. Med. 5, 953.

de Haan, L., de Haan, H., Olivier, B., Verster, J., 2012b. Alcohol mixed with energy drinks: methodology and design of the Utrecht student survey. Int. J. Gen. Med. 5, 889-898.

de Haan, L., Kuipers, E., Kuerten, Y., van Laar, M., Olivier, B., Verster, J.C., 2011. The RT-18: a new screening tool to assess young adult risk-taking behavior. Int. J. Gen. Med. 4, 575-584, http://dx.doi.org/10.2147/IJGM.S23603

Dick, D.M., Smith, G., Olausson, P., Mitchell, S.H., Leeman, R.F., O’Malley, S.S., Sher, K., 2010. Review: understanding the construct of impulsivity and its relationship to alcohol use disorders. Addict. Biol. 15, 217-226.

Eysenck, S.B.G., Pearson, P.R., Easting, G., Allsopp, J.F., 1985. Age norms for impulsiveness, venturesomeness and empathy in adults. Pers. Indiv. Differ. 6, 613-619.

Feil, J., Hasking, P., 2008. The relationship between personality, coping strategies and alcohol use. Addict. Res. Theor. 16, 526-537.

Hittner, J.B., Swickert, R., 2006. Sensation seeking and alcohol use: a meta-analytic review. Addict. Behav. 31, 1383-1401.

Ibáñez, M.I., Moya, J., Villa, H., Mezquita, L., Ruiperez, M., Ortet, G., 2010. Basic personality dimensions and alcohol consumption in young adults. Pers. Indiv. Differ. 48, 171-176.
Jaarverslag Universiteit Utrecht, 2013. Yearly Report Utrecht University 2013 Retrieved from http://www.jaarverslaguu.nl/ (accessed 05.06.15).

Kleiner, K.D., Gold, M.S., Frostpineda, K., Lenzbrunsman, B., Perri, M.G., Jacobs, W.S., 2004. Body mass index and alcohol use. J. Addict. Dis. 23, 105-118.

King, A.C., Bernardy, N.C., Hauner, K., 2003. Stressful events, personality, and mood disturbance: gender differences in alcoholics and problem drinkers. Addict. Behav. 28, 171-187.

Van Laar, M.W., Cruts, A.A.N., van Ooyen-Houben, M.M.J., Meijer, R.F., Croes, E.A., Ketelaars, A.P.M., 2012. Nationale Drug Monitor. Trimbos Instituut.

Lovibond, S.H., Lovibond, P.F., 1995. Manual for the Depression Anxiety Stress Scales, 2nd ed. Psychology Foundation Monograph, University of New South Wales, Sydney, Australia.

McLean, C.P., Anderson, E.R., 2009. Brave men and timid women? A review of the gender differences in fear and anxiety. Clin. Psychol. Rev. 29, 496-505.

Nolen-Hoeksema, S., 2004. Gender differences in risk factors and consequences for alcohol use and problems. Clin. Psychol. Rev. 24, 981-1010.

Nolen-Hoeksema, S., Girgus, J.S., 1994. The emergence of gender differences in depression during adolescence. Psychol. Bull. 115, 424

Onderwijs in cijfers [Education in numbers], 2015. Retrieved from http://www onderwijsincijfers.nl/ (accessed 05.06.15).

Parent, E.C., Newman, D.L., 1999. The role of sensation-seeking in alcohol use and risk-taking behavior among college women. J. Alcohol Drug Educ. 44, 12-28.

RCoreTeam, 2014. R: A Language and Environment for Statistical Computing. R Foundation for Statistical Computing, Vienna, Austria.

Reed, M.B., Wang, R., Shillington, A.M., Clapp, J.D., Lange, J.E., 2007. The relationship between alcohol use and cigarette smoking in a sample of undergraduate college students. Addict. Behav. 32, 449-464.

Rounsaville, B.J., Kranzler, H.R., Ball, S., Tennen, H., Poling, J., Triffleman, E., 1998. Personality disorders in substance abusers: relation to substance use. J. Nerv. Ment. Dis. 186, 87-95

Rutledge, P.C., Sher, K.J., 2001. Heavy drinking from the freshman year into early young adulthood: the roles of stress, tension-reduction drinking motives, gender and personality. J. Stud. Alcohol Drugs 62, 457.

Smarandescu, L., Walker, D., Wansink, B., 2014. Mindless drinking: how gender and BMI relate to the consumption of alcohol. Int. J. Drug Policy 25 1131-1134.

Sobell, L.C., Agrawal, S., Sobell, M.B., Leo, G.I., Young, L.J., Cunningham, J.A., Simco, E.R., 2003. Comparison of a quick drinking screen with the timeline followback for individuals with alcohol problems. J. Stud. Alcohol Drugs 64, 858.

Steinberg, L., Albert, D., Cauffman, E., Banich, M., Graham, S., Woolard, J., 2008. Age differences in sensation seeking and impulsivity as indexed by behavior and self-report: evidence for a dual systems model. Dev. Psychol. 44, 1764.

de Visser, R.O., McDonnell, E.J., 2012. "That's OK. He's a guy”: a mixed-methods study of gender double-standards for alcohol use. Psychol. Health 27, 618-639.

Wechsler, H., Dowdall, G.W., Davenport, A., Castillo, S., 1995a. Correlates of college student binge drinking. Am. J. Public Health 85, 921-926.

Wechsler, H., Dowdall, G.W., Davenport, A., Rimm, E.B., 1995b. A gender-specific measure of binge drinking among college students. Am. J. Public Health 85 , 982-985.

World Health Organization, 2014. Global Status Report on Alcohol and Health 2014. World Health Organization, Geneva.

Zuckerman, M., 2002. Zuckerman-Kuhlman Personality Questionnaire (ZKPO): an alternative five-factorial model. In: de Raad, B., Peruginig, M. (Eds.), Big Five Assessment. Hogrefe and Huber, Seattle, pp. 377-396. 